\title{
Type 2 diabetes mellitus in glucose-6-phosphate dehydrogenase deficient individuals in a Ghanaian population
}

\author{
Perez Quartey*, Bright Afriyie Owusu, Daniel Taylor, Eliza-Bertha Adomako
}

Department of Medical Laboratory Technology, Garden City University College, Kenyase, Ghana

Received: 22 September 2020

Revised: 02 November 2020

Accepted: 03 November 2020

\author{
*Correspondence: \\ Dr. Perez Quartey, \\ E-mail: quartey.perez@gcuc.edu.gh
}

Copyright: () the author(s), publisher and licensee Medip Academy. This is an open-access article distributed under the terms of the Creative Commons Attribution Non-Commercial License, which permits unrestricted non-commercial use, distribution, and reproduction in any medium, provided the original work is properly cited.

\begin{abstract}
Background: Studies in different populations have shown an association between diabetes mellitus and G6PD deficiency. This association has not been investigated in the Ghanaian population. We conducted a cross-sectional study to investigate the relationship between G6PD deficiency and type 2 diabetes mellitus in a Ghanaian population.

Methods: The cross-sectional study involved 125 registered type 2 diabetes mellitus clients and 125 non-diabetic individuals. Chi-square analysis was used to assess the association between G6PD status and type 2 diabetes mellitus with statistical significance pegged at $\mathrm{p}$-value $<0.05$.

Results: The prevalence of G6PD deficiency in the study population was $24.0 \%$ and $13.6 \%$ for the diabetics and nondiabetics respectively. In terms of gender, $29.5 \%$ of the diabetic males were G6PD deficient whiles G6PD deficiency was observed in $11.1 \%$ of the non-diabetic males. Additionally, $21.0 \%$ of the diabetic females were also G6PD deficient with $15.3 \%$ of the non-diabetic females being G6PD deficient. The results showed that the overall G6PD deficiency was significantly associated with type 2 diabetes mellitus as compared to the non-diabetics. In terms of gender differences, G6PD deficiency was significantly associated with type 2 diabetes in males but, there was no significant association in females.

Conclusions: The study reports the first findings of the relationship between G6PD deficiencies among type 2 diabetes patients in Ghana. The study revealed that G6PD deficiency is more prevalent among type 2 diabetics than non-diabetics. Type 2 diabetes mellitus is independently associated with G6PD deficiency in males but not females.
\end{abstract}

Keywords: G6PD deficiency, Ghanaians adults, Type 2 diabetes mellitus

\section{INTRODUCTION}

The regeneration of reduced glutathione (GSH), required for reduction of oxidative stress in the biological system is dependent on the reduced form of NicotinamideAdenine-Dinucleotide Phosphate coenzyme (NADPH). ${ }^{1}$ Glucose-6-Phosphate Dehydrogenase (G6PD) acts as the central regulatory enzyme in the metabolic pathway for the regeneration of NADPH. ${ }^{1}$ G6PD deficiency is a common enzyme defect resulting from mutation in the G6PD gene, estimated to be affecting over 400 million people worldwide with significantly higher frequencies recorded in Africa, Asia, and the Mediterranean area. ${ }^{2}$
The prevalence among males have been reported to be significantly higher among males than females. ${ }^{2,3}$ The WHO also estimates the prevalence of G6PD deficiency in Ghana to be $15-26 \% .^{4}$ Studies in different populations have shown an association between type 2 diabetes mellitus and G6PD deficiency. ${ }^{5-9}$ The relationship, however, is still matter of debate. This association has not been investigated in the Ghanaian population. The overall aim of this cross-sectional study was to investigate the association of G6PD deficiency and type 2 diabetes mellitus in a Ghanaian population. 


\section{METHODS}

\section{Study site and design}

The cross-sectional study was carried out at Agoroyesum Government Hospital in the Ashanti region between January 2020 to March 2020.

\section{Selection criteria}

The study included both registered type 2 diabetes mellitus clients (125) at the Diabetes clinic and nondiabetic individuals (125). Non-diabetic subjects were recruited from among blood donors and non-diabetic staff of the hospital.

\section{Measurements and statistical analysis}

Fasting blood glucose was measured with a Cobas Integra 400 plus autoanalyzer and the methaemoglobin reduction test assay was used to screen for G6PD status. Chi-square analysis was used to assess the association between G6PD status and type 2 diabetes mellitus with statistical significance pegged at $\mathrm{p}$-value $<0.05$.

\section{RESULTS}

\section{Demographic characteristics of the study participants}

The subjects were made up of $44(35.2 \%)$ diabetic males and $53(42.4 \%)$ non-diabetic males. The females included $81(64.8 \%)$ diabetics and $72(57.6 \%)$ non-diabetics. There was no significant difference in the gender distribution (Table 1).

\section{Table 1: Demographic characteristics of the study} participants.

\begin{tabular}{|llll|}
\hline Variable & Type 2 diabetics & Non-diabetics & P value \\
Gender & & & 0.243 \\
\hline Males & $44(35.2 \%)$ & $53(42.4 \%)$ & \\
\hline Females & $81(64.8 \%)$ & $72(57.6 \%)$ & \\
\hline Age (yrs) & $53.3 \pm 12.9$ & $42.7 \pm 8.78$ & $<0.0001$ \\
\hline
\end{tabular}

Results are presented as number $(\%)$ and mean \pm standard deviation

\section{Distribution of G6PD deficiency in the study population}

The results showed that the overall prevalence of G6PD deficiency in the study population was $24.0 \%$ and $13.6 \%$ for the diabetics and non-diabetics respectively. In terms of gender, $29.5 \%$ of the diabetic males were G6PD deficient whiles G6PD deficiency was observed in $11.1 \%$ of the non-diabetic males. Additionally, $21.0 \%$ of the diabetic females were also G6PD deficient with $15.3 \%$ of the non-diabetic females being G6PD deficient (Table 2).
Table 2: Distribution of G6PD deficiency in the study population.

\begin{tabular}{|lll|}
\hline G6PD status & Diabetics & Non-diabetics \\
\hline No Defect & & \\
\hline Males & $31(70.5 \%)$ & $47(88.7 \%)$ \\
\hline Females & $64(79.0 \%$ & $61(84.7 \%)$ \\
\hline Total & $95(76.0 \%)$ & $108(86.4)$ \\
\hline G6PD deficiency & & \\
\hline Males & $13(29.5 \%)$ & $6(11.3 \%)$ \\
\hline Females & $17(21.0 \%)$ & $11(15.3 \%)$ \\
\hline Total & $30(24.0 \%)$ & $17(13.6 \%)$ \\
\hline Resuts are presen)
\end{tabular}

Results are presented as number $(\%)$

\section{Association between G6PD and type 2 diabetes mellitus}

The results showed that the overall G6PD deficiency was significantly associated with type 2 diabetes as compared to the non-diabetics. In terms of gender differences, G6PD deficiency was significantly associated with type 2 diabetes in males but, there was no significant association in females (Table 3).

Table 3: Chi-square analysis of association between G6PD and type 2 diabetes mellitus.

\begin{tabular}{|llll|}
\hline Group & OR & 95\% C.I & P value \\
\hline Males & 3.56 & 1.28 to 9.03 & 0.012 \\
\hline Females & 1.30 & 0.54 to 3.05 & 0.566 \\
\hline Total & 2.01 & 1.05 to 3.93 & 0.035 \\
\hline
\end{tabular}

OR: Odds ratio; C.I: $95 \%$ Confidence interval

\section{DISCUSSION}

There was no significant sex difference between the type 2 diabetes group and the non-diabetic controls. However, the type 2 diabetes groupwere significantly older subjects as compared to the non-diabetic controls. This demographic picture of the participants in the study was similar to that of Engwa et al though the number of subjects in this present study was higher. ${ }^{5}$ G6PD is a sexlinked genetic disorder which when present manifests from birth and therefore not age-dependent. The results showed that the overall prevalence of G6PD deficiency in the study population was significantly higher among type 2 diabetics as compared to non-diabetics. This finding was consistent with other works in different populations that have also reported higher proportions of G6PD deficiency among type 2 diabetes clients. ${ }^{5-9}$ Similar to G6PD, evidence for a strong genetic element of type 2 diabetes susceptibility is suggested by the high incidence in certain racial/ethnic populations, high incidence among first-degree relatives of persons with type 2 diabetes mellitus and the high concordance among monozygotic twins relative to dizygotic twins. ${ }^{10-13}$ The results of the study showed that in this terms of gender differences, G6PD deficiency was significantly associated with type 2 diabetes in males but, there was no significant association in females. This suggests that G6PD deficiency is 
independently associated with type 2 diabetes in males but not in females. G6PD deficiency being an X-linked genetic abnormality, manifests its pathophysiology more profound in males than in females who may be heterozygous. This may account for the strong association of G6PD deficiency with type 2 diabetes in males than in females. However, the exact biochemical or metabolic mechanism for the relationship between type 2 diabetes mellitus and G6PD deficiency is still not defined and a matter of debate. The complex pathophysiologic nature of type 2 diabetes mellitus suggests that multiple physio-metabolic pathways are implicated in the development and progression of the disease. Several studies aimed at identifying genetic loci for determinants of the condition have been conducted. ${ }^{14,15}$ The identification of specific susceptibility loci for type 2 diabetes mellitus have been a challenge. This difficulty may be due to the combination of multiple genes involved and the interplay of many modifiable environmental contributing factors. ${ }^{14}$ It is not known whether the two conditions are co-inherited or one acts as a predisposing factor for the development of the other. However, reported findings from some researches have suggested the hypothesis that through oxidative stress G6PD deficiency may act as a risk factor for the development of diabetes.by some. ${ }^{6,16}$ With the established role of oxidative stress in the development and progression of diabetes complications, it has been suggested that G6PD-induced oxidative stress may be the key link for the association between diabetes and the enzymopathy. However, observation of such a link was not identified in the work by Engwa et al. ${ }^{5}$

Limitation of the study is that, study adds to the literature on the relationship between type 2 diabetes mellitus and G6PD deficiency. The study design however, does not purposively allude a causative link between the two conditions.

\section{CONCLUSION}

The study reports the first findings of the relationship between G6PD deficiency among type 2 diabetes mellitus clients in Ghana. The study revealed that G6PD deficiency is more prevalent among type 2 diabetics than non-diabetics. The study also concludes that type 2 diabetes is independently associated with G6PD deficiency in males but not females. Further studies using a larger sample size and designed to identify potential causal link between the two conditions will go a long way in elucidating this observed relationship between the two conditions.

Funding: No funding sources Conflict of interest: None declared

Ethical approval: The study was approved by the Institutional Ethics Committee

\section{REFERENCES}

1. Kletzien RF, Harris PK, Foellmi LA. Glucose-6phosphate dehydrogenase: a "housekeeping" enzyme subject to tissue-specific regulation by hormones, nutrients, and oxidant stress. FASEB J. 1994;8:174-81.

2. Luzzatto L, Nannelli C, Notaro R. Glucose-6Phosphate Dehydrogenase Deficiency. Hematol Oncol Clin North Am. 2016;30:373-93.

3. Nkhoma ET, Poole C, Vannappagari V, Hall SA, Beutler E. The global prevalence of glucose-6phosphate dehydrogenase deficiency: a systematic review and meta-analysis. Blood Cells Mol Dis. 2009;42:267-78.

4. WHO Working Group. Glucose-6-phosphate dehydrogenase deficiency. Bull World Health Organ 1989;67:601-11.

5. Engwa GA, Nwalo FN, Chibuzor GE, Ejiagha EC, Abonyi MC, Ugwu TE, et al. Relationship between Type 2 Diabetes and Glucose-6Phosphate Dehydrogenase (G6PD) Deficiency and Their Effect on Oxidative Stress. J Diabetes Metab. 2018;9:800.

6. Gaskin RS, Estwick D, Pedi R. G6PD deficiency: its role in the high prevalence of diabetes mellitus. Ethn Dis. 2001;11:749-54.

7. Lai YK, Lai NM, Lee SWH. Glucose-6-phosphate dehydrogenase deficiency and risk of diabetes: a systematic review and meta-analysis. Annals Hematol. 2017;(96):839-45.

8. Santana MS, Monteiro WM, Costa MRF, Sampaio VS, Brito MAM, Marcus VG, et al. High Frequency of Diabetes and Impaired Fasting Glucose in Patients with Glucose-6-Phosphate Dehydrogenase Deficiency in the Western Brazilian Amazon. Am J Trop Med Hyg. 2014;91(1):74-6.

9. Heymann AD, Cohen Y, Chodick G. Glucose-6Phosphate Dehydrogenase Deficiency and Type 2 Diabetes. Diabetes Care. 2012;35(8):e58-8.

10. Centers for Disease Control and Prevention. National diabetes fact sheet: general information and national estimates on diabetes in the United States, 2003. Rev ed. Atlanta (GA): U.S. Department of Health and Human Services, Centers for Disease Control and Prevention; 2004.

11. Bishop DB, Zimmerman BR, Roesler JS. Diabetes. In: Brownson RC, Remington PL, Davis JR, editors. Chronic disease epidemiology and control. 2nd edition. Washington (DC): Am Pub Heal Asso. 1998:421-64.

12. Lee ET, Welty TK, Cowan LD, Wang W, Rhoades DA, Devereux R, et al. Incidence of diabetes in American Indians of three geographic areas, the Strong Heart study. Diabetes Care. 2002;25(1):4954.

13. Matsuda A, Kuzuya T. Relationship between obesity and concordance rate for type 2 (noninsulin-dependent) diabetes mellitus among twins. Diabetes Res Clin Pract 1994;26:137-43. 
14. Busch CP, Hegele RA. Genetic determinants of type 2 diabetes mellitus. Clin Genet. 2001;60:243-54.

15. Klupa T, Malecki MT, Pezzolesi M, Ji L, Curtis S, Langefeld CD, et al. Further evidence for a susceptibility locus for type 2 diabetes on chromosome 20q13.1-q13.2. Diabetes 2000;49:2212-6.

16. Pes GM, Parodi G, Dore MP. Glucose-6-phosphate dehydrogenase deficiency and risk of cardiovascular disease: A propensity score-matched study. Atherosclerosis. 2019;282:148-53.

Cite this article as: Quartey P, Owusu BA, Taylor $\mathrm{D}$, Adomako EB. Type 2 diabetes mellitus in glucose-6-phosphate dehydrogenase deficient individuals in a Ghanaian population. Int $\mathrm{J}$ Res Med Sci 2020;8:4348-51. 